\title{
Short-Run Analysis of Fiscal Policy and the Current Account in a Finite Horizon Model*
}

This paper utilizes a technique developed by Judd to quantify the short-run effects of fiscal policies and income shocks on the current account in a small open economy. It is found that: (1) a future increase in govemment spending improves the short-run current account; (2) a future tax increase worsens the short-run current account; (3) a present increase in the govemment spending worsens the short-run current account dollar by dollar, while a present increase in the income improves the current account dollar by dollar; (4) when govemment budget is balanced in the long run, a tax cut accompanied by an equal government spending cut in the future always leads to a deterioration in the short-run current account.

\section{Introduction}

This paper examines the short-run effects of fiscal policies and income shocks on the current account in a small open economy. It differs from most of the existing studies by utilizing the approach developed by Judd (1982, 1985,1987 ) to quantify the short-run impact on the current account of intertemporal policy and income changes. While many studies have relied on phase diagrams or long-run equilibrium to derive certain qualitative, shortrun results (see Obstfeld 1981, 1982; Matsuyama 1987; Pitchford 1989; Sen and Turnovsky 1989, among many others), the Judd approach, with the help of the Laplace transform, can provide an exact quantitative expression for the short-run effects on the current account of different (temporary or permanent, present or future) shocks. New insights derived from this approach have been seen in various studies on taxation and debt in Judd's own studies, and Dixit's (1990) study on the traditional Solow model and the q-theory of investment.

In this paper, I apply the Judd approach to the Yaari-Blanchard model and consider a small open economy where the representative agent maximizes a discounted utility over a finite horizon by choosing consumption and twoasset (foreign bond and domestic government bond) holdings. The YaariBlanchard model not only offers a very simple structure to study the current account and fiscal policies, it also guarantees the existence of the short-run

*I thank an anonymous referee for comments and suggestions in revising this paper. Some details of technical calculations are available from me upon request. Responsibility for the contents of the paper is solely mine and not of the World Bank. 


\section{Heng-fu Zou}

dynamics of consumption even when the time preference differs from the world interest rate. If I use the typical intertemporal model, an equilibrium can be achieved in this model when the time preference equals the world interest rate. But in this case consumption will always be a constant. If the time preference is not equal to the world interest rate, then consumption either keeps increasing or keeps decreasing. To introduce more interesting, short-run dynamics in this typical model, it is necessary to complicate the matter by assuming an imperfect world credit market as in Pitchford (1989) or by adding capital accumulation with adjustment cost to the model.

The Judd approach delivers many interesting findings regarding the short-run impacts of different shocks on the current account in the YaariBlanchard model: ( 1 ) a future increase in government spending improves the short-run current account; (2) a future tax increase worsens the short-run current account; (3) a present increase in the government spending worsens the short-run current account dollar by dollar while a present increase in the income improves the current account dollar by dollar. Thus the short-run consumption does not adjust to the present exogenous shocks and all impacts of present shocks fall upon the current account; (4) when government budget is balanced in the long run, a tax cut accompanied by an equal government spending cut in the future always leads to a deterioration in the short-run current account.

The paper is organized as follows. In Section 2 the Yaari-Blanchard model for a small open economy is briefly introduced. In Section 3 I focus on the short-run impacts of income and policy shocks on consumption and the current account. In Section 4 the effect on the current account of a balanced, long-run government budget constraint is studied. I conclude the paper in Section 5.

\section{The Yaari-Blanchard Model}

The set-up of the model is essentially taken from Blanchard (1985). I consider a small open economy in a world with perfect capital mobility. Assets available to the residents of the small open economy are foreign bonds and domestic govemment bonds. The returns on these two kinds of bonds are given by a constant world interest rate, $r$. Each representative agent in this economy faces a constant probability of death, $p$, throughout his life. It is further assumed that the population growth is zero, and at any instant of time a new cohort of size $p$ (by proper normalization) is bom. The expected remaining life for an agent of any age is $\int_{0}^{\infty} t p e^{-p t} d t=p^{-1}$, which is also taken as the time horizon. Finally, the size of the total population at any time $t$ is $\int_{-\infty}^{0} p e^{-p(t-s)} d t=1$. 
At any time $t$, let $c(s, t), y(s, t), a(s, t)$ and $h(s, t)$ denote consumption, noninterest income, nonhuman wealth and human wealth of a consumer bom at time $s$. Here $a(s, t)=b(s, t)+b^{*}(s, t)$, and $b$ is the government bonds and $b^{*}$ is the foreign bonds. Also denote the lump-sum tax on the agent at time $t$ as $T(t)$. Since the interest rate for nonhuman wealth is $r$, the dynamic budget constraint of the agent born at time $s$ is

$$
d a(s, t) / d t=r a(s, t)+p a(s, t)+y(s, t)-T(t)-c(s, t),
$$

where $p a(s, t)$ is the payment from the life insurance company as a result of the assumed existence of perfect annuity market in the Yaari-Blanchard model.

Let the instantaneous utility be logarithmic and let the time preference rate be $\theta$. The agent maximizes the expected utility:

$$
E_{t}\left[\int_{0}^{\infty} \log c(s, t) e^{\theta(t-v)} d v\right], \quad \theta>0 .
$$

Since the only uncertainty is about the time of death, the maximization is equivalent to maximizing

$$
\int_{0}^{\infty} \log c(s, v) e^{(\theta+p)(t-v)} d v .
$$

The combination of (1) and (2) yields the following equation of motion for consumption:

$$
c(s, t)=(p+\theta)[a(s, t)+h(s, t)],
$$

where $h(s, t)=\int_{t}^{\infty}[y(s, v)-T(v)] e^{(\theta+p)(t-v)} d v$.

Taking aggregation over the whole population at time $t$ and denoting the aggregate variables by uppercase letters,

$$
X(t)=\int_{-\infty}^{t} x(s, t) p e^{p(s-t)} d s, \text { for } x(s, t)=c(s, t), a(s, t) \text { and } h(s, t) .
$$

Thus $C(t)$ is aggregate consumption, $A(t)$ aggregate assets, and $H(t)$ aggregate human wealth. The dynamic equations of these aggregate variables are given by

$$
\begin{aligned}
& C=(\theta+p)(A+H), \\
& \dot{H}=(r+p) H-y+T, \\
& \dot{A}=r A+y-T-C .
\end{aligned}
$$




\section{Heng-fu Zou}

Integration of (5) while taking $y$ and $T$ constant becomes

$$
\int_{t}^{\infty} d\left[H e^{-(r+p) s}\right]=\int_{t}^{\infty}(T-y) e^{-(r+p) s} d s ;
$$

that is,

$$
H=(y-T) /(r+p),
$$

which is the present discounted value of the after-tax noninterest income. With $\left(5^{\prime}\right)$, we can write $(4)$ as

$$
C=(\theta+p)[A+(y-T) /(r+p)],
$$

which is the consumption function that appeared in Blanchard $(1985,241)$.

Let $g(t), T(t)$ and $B(t)$ be government spending, tax revenue, and accumulated government borrowing at time $t$, respectively. Then the govermment budget constraint is given by:

$$
\dot{B}=g+r B-T .
$$

Since $A=B+B^{*}$, the substitution of (7) into (6) yields the dynamic equation for the foreign bond holdings or the current account:

$$
\dot{B}^{*}=\mathrm{rB}^{*}+\mathrm{y}-\mathrm{C}-\mathrm{g} \text {. }
$$

Differentiating Equation ( $\left.4^{\prime}\right)$ and using (7) and (8), I have the equation of motion for aggregate consumption:

$$
\dot{C}=(r-p-\theta) C+p(p+\theta)(y-T) /(r+p) .
$$

Equations (7), (8) and (9) consist of a full dynamic system in $C, B$ and $B^{*}$. We also note that Equations (8) and (9) are two dynamic equations independent of the government budget constraint (7). In the following analysis, I will first study the subsystem of (8) and (9) and then proceed to consider the government budget constraint.

\section{Short-Run Impacts of Exogenous Shocks}

Blanchard (1985) has studied the effects of permanent shocks on consumption and the foreign bond holding by dealing with the steady-state equations of $\left(4^{\prime}\right),(8)$ and (9). My study here focuses on the short-run effects on consumption and the current account of different shocks, which can be permanent or temporary, present or future. As I said earlier, in dynamic economic analysis, many existing studies have utilized phase diagrams to derive certain qualitative results regarding the short-run effects; see Able (1982), Obstfeld (1981), and Sen and Turnovsky (1989), among others. To quantify the short-run effects of different shocks, I follow the Judd approach. 
Suppose that at time $t=0$ or today the foreign bond holdings and consumption are at the steady-state level corresponding to exogenous variables $y, g$ and $T$. In addition, the govemment budget is assumed to be balanced. At time $t=0$, let the exogenous variables change as follows:

$$
\begin{aligned}
& y^{\prime}(t)=y+\varepsilon h_{y}(t), \\
& g^{\prime}(t)=g+\varepsilon h_{g}(t), \\
& T^{\prime}(t)=T+\varepsilon h_{T}(t),
\end{aligned}
$$

where $\varepsilon$ is a parameter. Functions $h_{y}(t), h_{g}(t)$ and $h_{T}(t)$ are the intertemporal changes of the noninterest income, government spending and taxation, respectively. To give an example, let the government spending increase by $\varepsilon$ for the time interval $t_{1}<t<t_{2}$. Then $h_{g}(t)=1$ for $t_{1}<t<t_{2}$ and $h_{g}(t)=0$ otherwise; $g^{\prime}(t)=g+\varepsilon$ for $t_{1}<t<t_{2}$ and $g^{\prime}(t)=g$ otherwise.

Substituting $y^{\prime}(t), g^{\prime}(t)$ and $T^{\prime}(t)$ for the constants $y, g$ and $T$ in Equations (8) and (9), I have

$$
\begin{aligned}
\dot{C} & =(r-p-\theta) C+p(p+\theta)\left(y+\varepsilon h_{y}(t)-T-\varepsilon h_{T}(t)\right) /(r+p), \\
\dot{B}^{*} & =r B^{*}+y+\varepsilon h_{y}(t)-C-g-\varepsilon h_{g}(t),
\end{aligned}
$$

with boundary conditions $\lim _{\mathrm{t} \rightarrow \mathrm{n}} B^{*}(t) \mid<\infty, B^{*}(0)=B_{0}^{*}$. The solutions to (11) will depend on both time, $t$, and exogenous parameter, $\varepsilon$. I write the solutions as $C(t, \varepsilon)$ and $B^{*}(t, \varepsilon)$. These two functions are differentiable with respect to $\varepsilon$ because (11a) and (11b) are two linear differential equations. For $\varepsilon=0$, the system stays at the initial steady state. As $\varepsilon$ changes from zero to nonzero values, namely, as exogenous shocks occur, the impact on consumption and foreign asset accumulation at any time $t$ can be seen from the partial differentiation of $C$ and $B^{*}$ with respect to $\varepsilon$. To this end, I use the following notations:

$$
\begin{aligned}
\partial C(t, 0) / \partial \varepsilon & =C_{\varepsilon}(t), & & \partial B^{*}(t, 0) / \partial \varepsilon=B_{\varepsilon}^{*}(t), \\
\partial[\partial C(t, 0) / \partial t)] / \partial \varepsilon & =\dot{C}_{\varepsilon}(t), & & \left.\partial\left[\partial B^{*}(t, 0) / \partial t\right)\right] / \partial \varepsilon=\dot{B}_{\varepsilon}^{*}(t) .
\end{aligned}
$$

Differentiating Equations (11a) and (11b) with respect to $\varepsilon$ and evaluating the results at $\varepsilon=0$, I have

$$
\left[\begin{array}{c}
\dot{C}_{\varepsilon} \\
\dot{B}_{\varepsilon}^{*}
\end{array}\right]=\left[\begin{array}{cc}
(r-p-\theta) & 0 \\
-1 & r
\end{array}\right]\left[\begin{array}{l}
C_{\varepsilon} \\
B_{\varepsilon}^{*}
\end{array}\right]+\left[\begin{array}{c}
p(p+\theta)(r+p)^{-1}\left[h_{y}(t)-h_{T}(t)\right] \\
h_{y}(t)-h_{g}(t)
\end{array}\right] .
$$

Denote the $2 \times 2$ matrix in (12) as $J$. $J$ is the constant Jocobian matrix of the dynamic system. As it is clear from $J$, the initial equilibrium is saddlepoint stable if $(r-p-\theta)$ is negative, which is a stability condition assumed in 


\section{Heng-fu Zou}

Blanchard (1985) and Matsuyama (1987). With this assumption, one eigenvalue of the system is positive and one is negative:

and

$$
\mu=r
$$

$$
\omega=r-p-\theta,
$$

here $\mu(=r)$ is the positive eigenvalue and $\omega(=r-p-\theta)$ is the negative eigenvalue.

As in Judd (1985), the Laplace transform can be utilized to solve (12), a linear system with constant coefficients. The Laplace transform of a function, $f(t)(t>0)$, is another function, $F(s)$, defined for sufficiently large $s$ :

$$
F(s)=\int_{0}^{\infty} f(t) e^{-s t} d t
$$

Let $H C_{\varepsilon}(s), H B_{\varepsilon}^{*}(s), H_{y}(s), H_{\varepsilon}(s)$ and $H_{T}(s)$ be the Laplace transforms of $C_{\varepsilon}(t)$, $B_{\varepsilon}^{*}(t), h_{y}(t), h_{g}(t)$ and $h_{T}(t)$, respectively. Then apply the Laplace transform to $(12)$ :

$$
\begin{aligned}
& {\left[\begin{array}{l}
s H C_{\varepsilon}(s) \\
s H B_{\varepsilon}^{*}(s)
\end{array}\right]=J\left[\begin{array}{l}
H C_{\varepsilon}(s) \\
H B_{\varepsilon}^{*}(s)
\end{array}\right]\left[\begin{array}{c}
p(p+\theta)(r+p)^{-1}\left[H_{y}(s)-H_{T}(s)\right]+C_{\varepsilon}(0) \\
H_{y}(s)-H_{g}(s)
\end{array}\right] .} \\
& r, \\
& {\left[\begin{array}{l}
H C_{\varepsilon}(s) \\
H B_{\varepsilon}^{*}(s)
\end{array}\right]=\left[\begin{array}{cc}
(s-r+p+\theta) & -r \\
1 & s-r
\end{array}\right]\left[\begin{array}{c}
p(p+\theta)(r+p)^{-1}\left[H_{y}(s)-H_{T}(s)\right]+C_{\varepsilon}(0) \\
H_{y}(s)-H_{g}(s)
\end{array}\right] .}
\end{aligned}
$$

Solving the inverse matrix yields

$\left[\begin{array}{l}H C_{\varepsilon}(s) \\ H B_{\varepsilon}^{*}(s)\end{array}\right]=(s-r+p+\theta)^{-1}(s-r)^{-1}\left[\begin{array}{lr}(s-r) & 0 \\ -1 & s-r+p+\theta\end{array}\right]\left[\begin{array}{l}p(p+\theta)(r+p)^{-1}\left[H_{y}(s)-H_{T}(s)\right]+C_{\varepsilon}(0) \\ H_{y}(s)-H_{\mathrm{g}}(s)\end{array}\right]$.

In (14), $C_{\varepsilon}(0)$ is the initial change or jump in consumption corresponding to exogenous shocks. This jump is necessary for the system to converge to the steady state along the unique perfect foresight path. To determine $C_{\varepsilon}(0)$, note that the existence of a saddle-point equilibrium in this model implies a bounded steady-state foreign asset accumulation for any $\varepsilon$. Therefore $H B_{\varepsilon}^{*}(s)$ must be finite for any $s>0$; in particular, it is true for $s=\mu=r$ (the positive eigenvalue of the dynamic system). However, when $s=r$, the inverse matrix in (14) is singular. To remove this singularity, the numerator on the right-hand side of (14) has to be zero (see Judd 1987 for details):

$$
-p(p+\theta)(r+p)^{-1}\left[H_{y}(r)-H_{T}(r)\right]-C_{\varepsilon}(0)+(p+\theta)\left[H_{y}(r)-H_{g}(r)\right]=0,
$$


which is the same as

$$
C_{\varepsilon}(0)=r(p+\theta)(r+p)^{-1} H_{y}(r)-(p+\theta) H_{g}(r)+p(p+\theta)(r+p)^{-1} H_{T}(r) .
$$

Equation (15) gives the impact on the initial or today's consumption from future shocks in the noninterest income, government spending and tax. Since the Laplace transform can be regarded as the present discount value of future shocks, the effects of different shocks in the remote future will be much smaller than the ones in the near future. Also, the discount factor here is the world interest rate, $r$, which is not true in general. Usually, the discount rate is the positive eigenvalue of the dynamic system, but they coincide in our model here.

From (15), it is clear, any future increase in the noninterest income will increase today's consumption. Instead of just providing this qualitative information, expression (15) presents the exact magnitude of this effect. For example, let the increase in noninterest income happen in the future time $t: t_{1}<t<t_{1}+\Delta t$ and $\Delta t$ is very small. Then

$$
H_{y}(r)=\int_{0}^{\infty} h_{y}(t) e^{-r t} d t=\int_{t_{1}}^{t_{1}+\Delta t} e^{-r t} d t \cong \Delta t e^{-r t_{1}},
$$

and the initial consumption will increase by $r(p+\theta)(r+p)^{-1} \Delta t e^{-r_{1}}$.

Next, a tax rise in the future will also increase the initial consumption. In fact, if future tax follows the time path of the noninterest income, namely $H_{T}(r)=\Delta t e^{-r t_{1}}$, today's consumption will go up by $p(p+\theta)(r+p)^{-1} \Delta t e^{-r t_{1}}$. This is an interesting result because people act to consume more today instead of saving more to smooth their consumption in view of a future tax hike. To provide some economic intuition for this result, we note that, for a fixed government spending, $g$, over time, an increase in the future tax will lower government bond finance over time as indicated by the integration of the government budget constraint (7). To gradually reduce their government bond holdings, people react to this anticipated tax increase by converting part of their government bond holdings to consumption today. This is why there will be an increase in consumption at $t=0$ when the tax rises in the future.

Equation (15) also implies that an increase in future government spending will reduce today's consumption. The exact magnitude of this reduction is given by $(p+\theta) H_{g}(r)$. The economic intuition of this result is the following. From the integration of the government budget constraint (7), an increase in $\mathrm{g}$ in the future without raising the tax will lead to more government borrowing over time. Expecting an increase in government bonds, people reduce their consumption today and save more to purchase government bonds. Therefore, current consumption is lowered as a result of a future increase in government spending. A similar result has been obtained in Judd 


\section{Heng-fu Zou}

(1985). In a framework of a neoclassical growth model with income taxation and government borrowing, Judd shows that an increase in future government spending reduces consumption today and consequently encourages investment today; see Judd $(1985,311)$. I will show that in the finite horizon model the reduced consumption today improves today's current account.

Substituting (15) into (12), we can solve the initial impact of different shocks on the current account:

$$
\dot{B}_{\varepsilon}^{*}(0)=-C_{\varepsilon}(0)+h_{y}(0)-h_{g}(0),
$$

or

$\dot{B}_{\varepsilon}^{*}(0)=-r(p+\theta)(r+p)^{-1} H_{y}(r)+(p+\theta) H_{g}(r)-p(p+\theta)(r+p)^{-1} H_{T}(r)+h_{y}(0)-h_{g}(0)$

In deriving (16), I have used the fact that the initial foreign bond holding is given $\left(B^{*}(0)=B_{0}^{*}\right)$ and $B_{\varepsilon}^{*}(0) \equiv 0$ irrespective of $\varepsilon$; for this point, see Dixit (1990).

From (16), a few interesting points can be shown:

First, an increase in today's noninterest income will improve the current account dollar by dollar. This is given by the term $h_{y}(0)$ in (16). If the noninterest income rises today, that is, $h_{y}(0)=1$, the foreign bond holdings will also rise by one. On the contrary, an increase in government spending today worsens the current account dollar by dollar. Combining (15) and (16), I can show that, as exogenous shocks happen today, there is no adjustment on today's consumption and all impact of today's shocks falls upon the initial current account.

These results can also be seen directly from Equation (8) combined with Equation (14). Since, from (14), today's consumption does not react to any of today's exogenous shocks, and since the wealth stock-foreign bond holdings, $B^{*}$-cannot change initially, Equation (8) indicates that a rise in $y$ at time $t=0$ increases savings and the current account surplus, and a rise in $\mathrm{g}$ at time $t=0$ reduces savings and the current account surplus.

Second, any increase in future income reduces the initial current account balances, and its magnitude is just the opposite of the increase in the initial consumption, $-r(p+\theta)(r+p)^{-1} H_{y}(r)$. This is true because an anticipated future increase in $y$ raises wealth, stimulates consumption, decreases savings and worsens the current account today.

Third, a future increase in government spending improves the initial current account by $(p+\theta) H_{g}(r)$. The explanation for this result is closely related to our explanation about the negative effect of future government spending on today's consumption. Since more government spending in the future without raising the tax requires an increase in government bond issue over time, people respond today by lowering their consumption and saving 
more in the form of bond holdings. As today's consumption is reduced, some of this additional saving takes the form of more foreign asset holdings, and, thus, improves the current account today. As I said earlier, this stimulating effect of a future increase in government spending on the current account is very similar to the stimulating effect of government spending on investment in Judd (1985).

Finally, since a future increase in tax stimulates today's consumption as I have argued earlier, the economy will respond to a higher future tax by decumulating its foreign asset holdings and converting part of its foreign bonds to consumption today. The negative impact of a future tax increase on the initial current account is given by $-p(p+\theta)(r+p)^{-1} H_{T}(r)$ in (16).

\section{The Balanced Budget Condition}

I now return to the government budget constraint. When shocks are introduced into the government budget (7) in the form of Equations (10b) and $(10 \mathrm{c})$, the new budget constraint becomes

$$
\dot{B}=g+\varepsilon h_{g}(t)+r B-T-\varepsilon h_{T}(t) .
$$

Differentiating this equation with respect to $\varepsilon$ and assuming that the stock of $B$ at the initial steady state is zero, I find that, for a balanced budget, the following relation holds:

$$
H_{g}(r)-H_{T}(r)=0 ;
$$

that is, the present value of government spending has to equal the present value of tax, discounted at the world interest rate $r$. For example, if the tax is cut at time $t=0$, and later on the spending is also cut to balance the budget at time $t \geq \tau$, then $h_{T}(0)=-1$ today and the government spending has to be cut in the future by $h_{\mathrm{g}}(t)=-\gamma$ for $t \geq \tau$. Equation (18) requires that

$$
\mathrm{I}=\gamma \int_{\tau}^{\infty} e^{-r t} d t
$$

namely,

$$
\gamma=r e^{r \tau}
$$

Substituting the relation (18) into (15) and (16), we have

$$
\begin{aligned}
& C_{\varepsilon}(0)=r(p+\theta)(r+p)^{-1} H_{y}(r)+(p+\theta)\left[p(r+p)^{-1}-1\right] H_{T}(r) . \\
& \dot{B}_{\varepsilon}^{*}(0)=-r(p+\theta)(r+p)^{-1} H_{y}(r)+(p+\theta)\left[1-p(r+p)^{-1}\right] H_{T}(r)+h_{y}(0)-h_{g}(0) .
\end{aligned}
$$

Therefore, an increase in tax balanced by an increase in government spending in the future always leads to improvement in the initial current account 


\section{Heng-fu Zou}

because the term $\left[1-p(r+p)^{-1}\right]$ in $(20)$ is positive. Or put it in another way, a cut in tax balanced by a future cut in government spending always worsens the initial current account.

This finding can be explained as follows. In the finite horizon model, people have a nonzero probability to die at any time. With a future rise in tax, its effects on people born at different times are different, and a typical agent may not be taxed because he may die by the time more tax is actually collected. Similarly, the burden of more government spending may not be shared by a person due to the probability of his death. In this way, to a typical agent borm at time $t$, the one to one correspondence between the discounted tax and discounted government spending in the infinite horizon model does not hold here. In fact, in this model, a future rise in government spending causes a greater reduction in today's consumption than the increase of today's consumption caused by an equal rise in future tax. Therefore, when the effect of tax is dominated by the effect of government spending, an equal amount of increase in future tax and government spending brings about a decline in the initial consumption and an improvement in the initial current account.

\section{Summary}

This paper has applied the Judd approach to study the effects of fiscal policies and income shocks on the short-run current account. Among the many interesting results found here, I should emphasize the following three observations: First, the present shocks in income and fiscal policies only alter the short-run current account, while future shocks have an effect on both the short-run current account and short-run consumption. Second, there exists an asymmetry between the effect of tax and the effect of government spending on the current account. A tax rise in the future worsens the short-run current account, but an increase in future government spending improves the short-run current account. The Judd approach allows me to conclude that the effect of government spending dominates the effect of an equal tax rise. Therefore, finally, when the balanced government budget constraint is imposed, a future increase in government spending and tax leads to a current account surplus in the short run and a future cut in government spending and tax results in a current account deficit in the short run.

Received: November 1992

Final version: June 1993

\section{References}

Abel, Andrew B. "Dynamic Effect of Permanent and Temporary Tax Policies in a $q$ Model of Investment." Journal of Monetary Economics 9 (May 1982): 353-73. 
Blanchard, Olivier J. "Debt, Deficits and Finite Horizon." Journal of Political Economy 93 (April 1985): 223-47.

Dixit, A. "Growth Theory after Thirty Years." In Growth/Productivity/ Unemployment, edited by Peter Diamond, 3-22. Cambridge, MA: MIT Press, 1990.

Judd, Kenneth. "An Altemative to Steady State Comparison in Perfect Foresight Models." Economics Letters 10 (January 1982): 55-59.

- "Short-Run Analysis of Fiscal Policy in a Simple Perfect Foresight Model." Journal of Political Economy 93 (April 1985): 298-319.

- "Debt and Distortionary Taxation in a Simple Perfect Foresight Model." Journal of Monetary Economics 20 (July 1987): 51-72.

Matsuyama, Kiminori. "Current Account Dynamics in a Finite Horizon Model." Journal of International Economics 23 (November 1987): 299313.

Obstfeld, Maurice. "Macroeconomic Policy, Exchange-Rate Dynamics, and Optimal Asset Accumulation." Journal of Political Economy 89 (December 1981): 1142-161.

—_. "Aggregate Spending and the Terms of Trade: Is There A LaursenMetzler Effect?" Quarterly Journal of Economics 97 (May 1982): 251-70.

Pitchford, J. D. "Optimum Borrowing and the Current Account When There Are Fluctuations in Income." Journal of International Economics 26 (May 1989): 345-58.

Sen, Partha, and Stephen Turnovsky. "Deterioration of the Terms of Trade and Capital Accumulation: A Re-examination of the Laursen-Metzler Effect." Journal of International Economics 26 (May 1989): 227--50.

Solow, R. "Reactions to Conference Papers." In Growth/Productivity/ Unemployment, edited by Peter Diamond, 221-29. Cambridge, MA: MIT Press, 1990.

Yaari, Menahem. "Uncertain Lifetime, Life Insurance, and the Theory of Consumer." Review of Economic Studies 32 (April 1965): 137-50. 